\title{
GROUNDING LINES DETECTING USING LANDSAT8 OLI AND CRYOSAT-2 DATA FUSION
}

\author{
Fei $\mathrm{Li}^{1{ }^{1,},}$, Yunxi Guo ${ }^{1}$, Yu Zhang ${ }^{1, *}$, Shengkai Zhang ${ }^{1}$ \\ 1Chinese Antarctic Center of Surveying and Mapping, Wuhan University, China \\ -fli@whu.edu.cn, yuzhang_spl@whu.edu.cn
}

Commission III, WG III/9

KEY WORDS: Grounding line, Landsat8 OLI, Cryosat-2, K-means, Slope, Merge

\begin{abstract}
:
The grounding zone is the region where ice transitions from grounded ice sheet to freely floating ice shelf, grounding lines are actually more of a zone, typically over several kilometers. The mass loss from Antarctica is strongly linked to changes in the ice shelves and their grounding lines, since the variation in the grounding line can result in very rapid changes in glacier and ice-shelf behavior. Based on remote sensing observations, five global Antarctic grounding line products have been released internationally, including MOA, ASAID, ICESat, MEaSUREs, and Synthesized grounding lines. However, the five products could not provide the annual grounding line products of the whole Antarctic, even some products have stopped updating, which limits the time series analysis of Antarctic material balance to a certain extent. Besides, the accurate of single remote-sensing data based grounding line products is far from satisficed. Therefore, we use algorithms to extract grounding lines with SAR and Cryosat-2 data respectively, and combine the results of two kinds of grounding lines to obtain new products, we obtain a mature grounding line extraction algorithm process, so that we can realize the extraction of grounding line of the Antarctic each year in the future. The comparison between fusion results and the MOA product results indicate that there is a maximum deviation of 188.67 meters between the MOA product and the fusion result.
\end{abstract}

\section{INTRODUCTION}

The grounding line is a fundamental transition for ice dynamics. It is the locus of a major shift in ice flow from shear-dominated, basal-drag-controlled ice stream flow to drag-free, side-shearcontrolled, gravity spreading of floating ice shelves onto the ocean. Knowing the position of the grounding line is critical for mass budget calculations because it determines the precise location of where ice detaches from the bed and becomes afloat in the ocean, typically far upstream (10 to $1,000 \mathrm{~km})$ from where ice calves into icebergs. It is near the grounding line that ice shelves experience the largest rates of melting by the ocean.

For grounding line detection, remote sensing plays an important role by extracting the topography or elevation between sea ice shelf and grounding line zone. At present, there are four kinds of technics, namely hydrostatic balance, slope analysis, repeated orbit analysis and differential interferometry. The Antarctic and the Arctic sea ice changes show the opposite growth trend. To understand the interaction between Antarctic sea ice change and the grounding line's advance and retreat, it is urgent to require precise, long time series and full coverage grounding lines products. Especially in the face of frequent occurrences of extreme weather events in recent years, improving the grounding line extraction method and high precision to extract grounding lines, expanding grounding lines research time scale and the whole Antarctic long sequence of grounding line dynamic change monitoring, in-depth analysis of the relationship of the grounding line change and climate change, will provide effective reference on the material balance and its estimation.

Considering that existing products are mostly extracted by multiple data sources, such as MOA, Synthesized grounding lines, and the most accurate MEaSUREs products, there are relatively new, widely covered, and time-continuous Cryosat-2 elevation data sources. We consider using an algorithm to extract the ground line by combining optical image and cryosat2 elevation data. We chose a region near Zhongshan Station in Prydz Bay as the preliminary test area, selected Landsat 8 OLI data from October 2015 and selected October 2015 Cryosat-2 elevation data. We first use the k-means algorithm to extract the characteristics of the optical image, filter the feature area, get the ground line area, and then fit the elevation data plane, we obtain the plane gradient abrupt change area by the plane slope analysis, as the ground line area.Finally, fuse the areas obtained by the two algorithms to obtain the final grounding line.

\section{METHODOLOGY}

\section{1 k-means algorithm for the grounding lines detection in Landsat8 imagery}

According to optical image texture feature, we through K-means clustering of Landsat8 optical image segmentation, and then through the standard deviation as a qualification, median filter for extracting areas at the same time to detect the selected area of the grounding line. This algorithm only needs to input the 
parameter $\mathrm{k}$ and read the optical image to automatically extract the result without excessive manual operation. The algorithm is simple and efficient.

$\mathrm{K}$-means algorithm is to cluster the samples into $\mathrm{K}$ clusters, and the specific algorithm is described as follows:

(1) $\mathrm{K}$ cluster center point is selected randomly as: $\mu_{1}, \mu_{2, \ldots,} \mu_{k} \in R^{n}$

(2) Repeat the following process until convergence: for each sample I, calculate the class that it should belong to

$$
c^{i}=\arg \min _{\tilde{j}}\left\|x^{(i)}-\mu_{j}\right\|^{2}
$$

Recalculate the centroid of each class of $\mathrm{j}$ :

$$
\mu_{i}=\frac{\sum_{i=1}^{m} 1\left\{c^{(i)}=j\right\} x^{(i)}}{\sum_{i=1}^{m} 1\left\{c^{(i)}=j\right\}}
$$

\subsection{Slope analysis}

For the Cryosat-2 elevation data, Kriging interpolation method is used to transform a plane, which will be used to obtain the gradient mutation through slope analyzing procedure. Finally, the data points with largest gradient is labeled as the grounding line points. Using the slope to detect the ground line can be divided into two methods: (1) Using the high-precision DEM to generate the slope map to extract the ground line; (2) Using the gradient change to extract the ground line from the difference in brightness caused by the visible light image.

There are four kinds of slope methods: percentage method, degree method, density method and fractional method. This article uses the percentage method and the degree method:

(1) Percentage method: the percentage of elevation and horizontal distance between two points.

(2) Degree method: The gradient is expressed in degrees and calculated using an inverse trigonometric function. The slope calculation generally uses a fitting surface algorithm. The fitting surface generally uses a quadric surface, ie a $3 \times 3$ window, Figure 1. The center of each window is an elevation point, and the calculation formula is:

$$
\text { Slope }=\tan \sqrt{\text { Slop } \theta_{\text {We }}^{2}+\operatorname{Slop} \theta_{\mathrm{gn}}^{2}}
$$

In the formula, Slope $\theta_{w e}$ is the slope of the $\mathrm{x}$ direction, and slope $e_{\text {sn }}$ is the slope of the y direction.

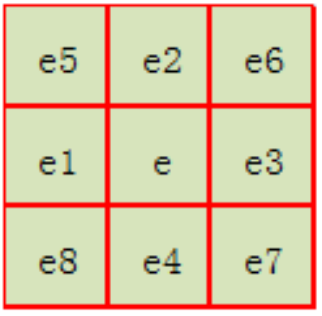

Fig.1. $3 \times 3$ window

The calculation of Slope $e_{w e}$ and Slope $e_{\text {sn }}$ can be used in several common methods:
Algorithm 1:
a) Slope $e_{w e}=\frac{\theta_{1}-\theta_{3}}{2 * \text { Cellsize }}$
b) Slope $e_{\text {sn }}=\frac{e_{4}-\theta_{2}}{2 * \text { Cellsize }}$

Algorithm 2:

a) Slope $_{w e}=\frac{\left(e_{8}+2 e_{1}+e_{5}\right)-\left(e_{7}+2 e_{3}+e_{6}\right)}{8 * \text { Cellsize }}$

b) Slope $e_{\text {sn }}=\frac{\left(e_{7}+2 e_{4}+e_{8}\right)-\left(e_{6}+2 e_{2}+e_{5}\right)}{8 * \text { Cellsige }}$

Algorithm 3:

a) Slope $e_{\text {we }}=\frac{\left(e_{8}+e_{1}+e_{5}\right)-\left(e_{7}+e_{3}+e_{6}\right)}{8 * \text { Cellsize }}$

b) Slope $_{\text {on }}=\frac{\left(e_{7}+e_{4}+e_{8}\right)-\left(e_{6}+e_{2}+e_{5}\right)}{8 * \text { Cellsize }}$

The Cell Size in the formula is the interval length of the grid DEM. Algorithm 1 has the highest accuracy and the highest computational efficiency. We use algorithm 2 in this paper.

\subsection{Merge algorithms}

The ground lines were extracted using the texture features of the optical image and the croysat-2 elevation data respectively, and the new ground line products were obtained through the fusion algorithm and weight adjustment, which includes optical texture feature points and elevation information points. Algorithm process shown in Figure 2.

In this paper, the weighted fusion algorithm is used directly to calculate the correlation coefficients of the pixel values of the two images as weights, and obtain the geographical coordinates of the image and its corresponding pixel values respectively. The pixel values of the overlapping area of the optical image result and the croysat- 2 calculation result are integrated by a weighted algorithm to obtain a fusion. The image is the final calculation result. In the later stages, different data will be attempted to obtain a fusion ground line using an improved adaptive weighting algorithm.

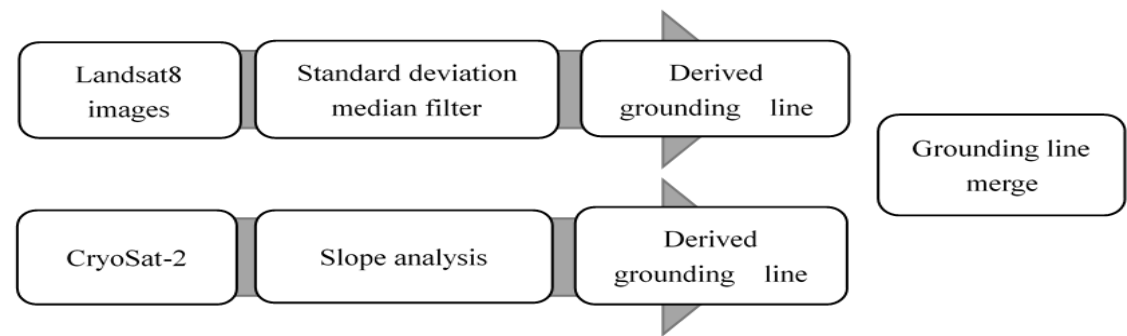

Fig.2. Algorithm process 


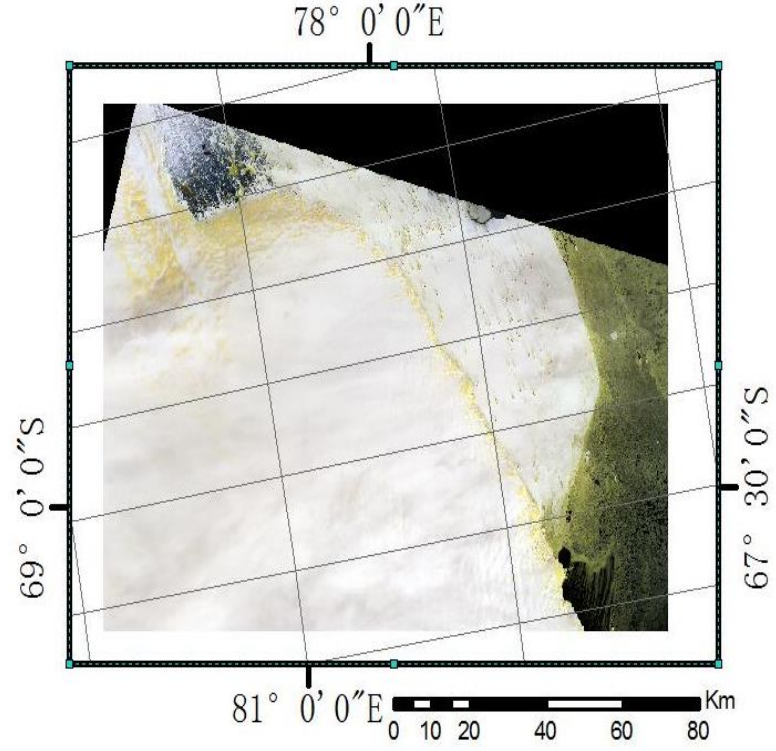

(a)

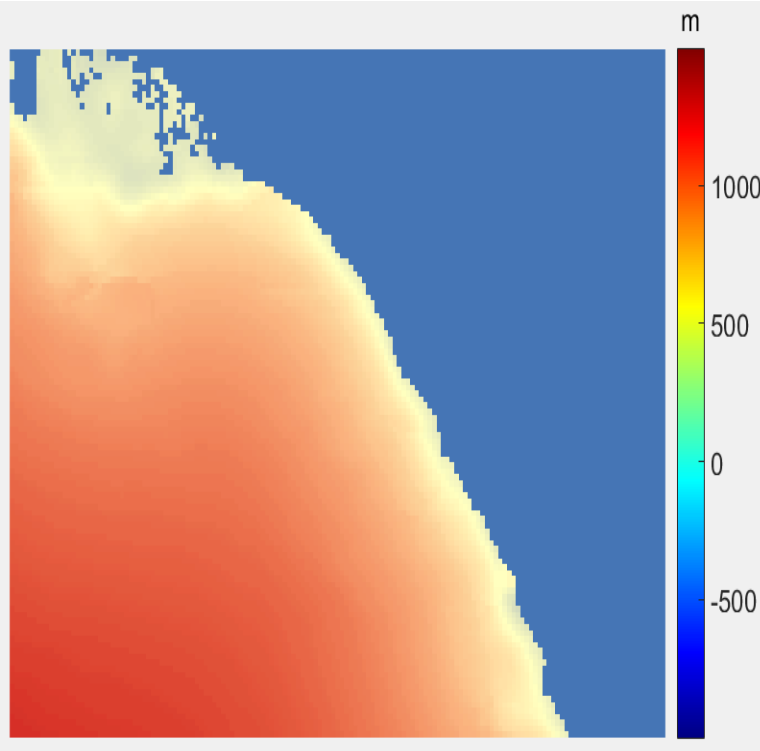

(b)

Fig.3. (a) Landsat-8 OLI image; (b) DEM of the selected region using croysat-2 elevation data

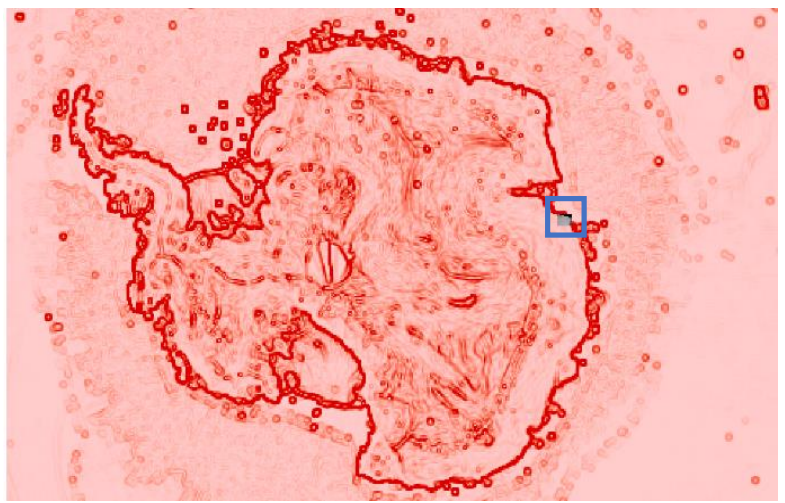

(a)

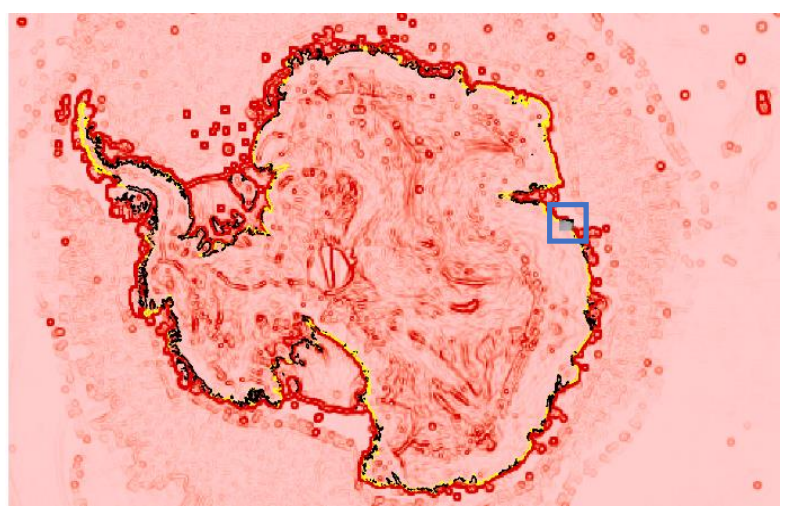

(c)

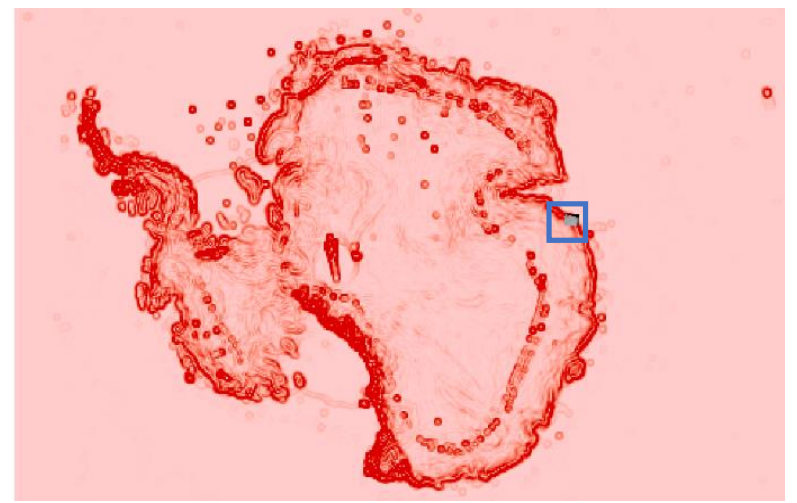

(b)

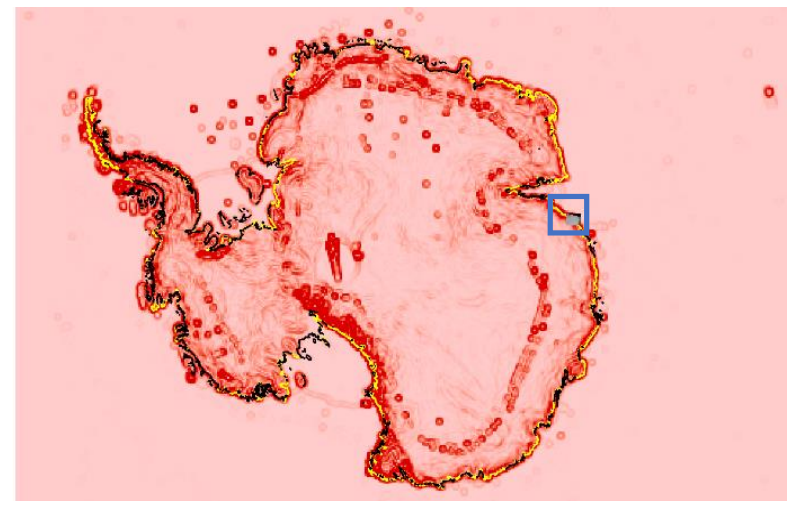

(d)

MOA product

MEaSUREs product

Fig.4.(a) the degree representation result;(b) the percentage representation result;(c) The result of the degree representation result extraction(the red line), the existing Moa product(the yellow line) and the InSAR_GL_Antarctica product(the black line);(d) The result of the percentage representation result extraction(the red line), the existing Moa product(the yellow line) and the InSAR_GL_Antarctica product(the black line) 


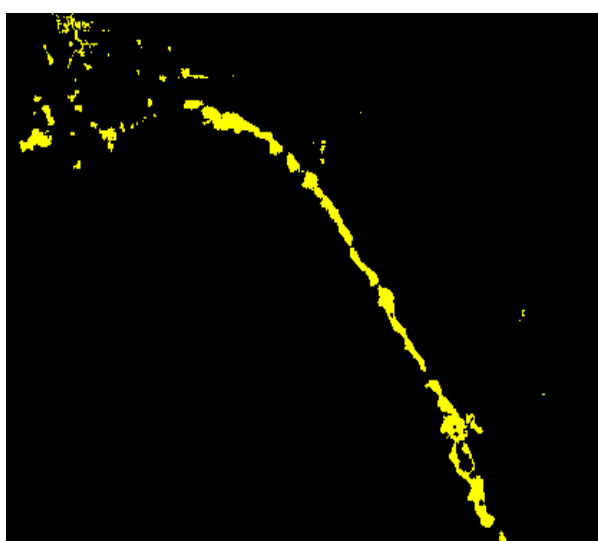

(a)

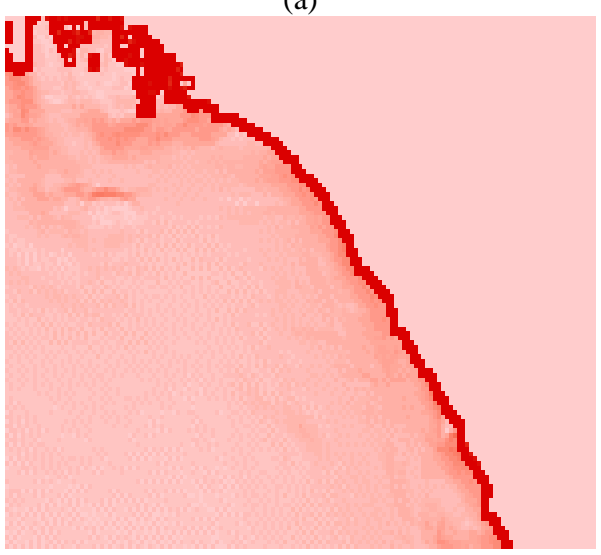

(c)

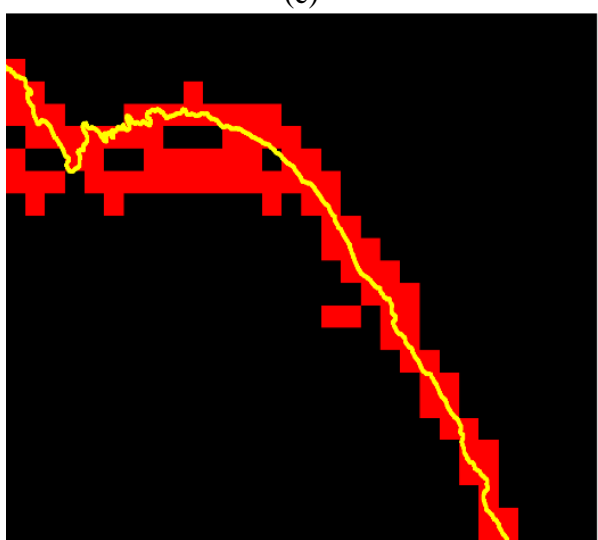

(e)

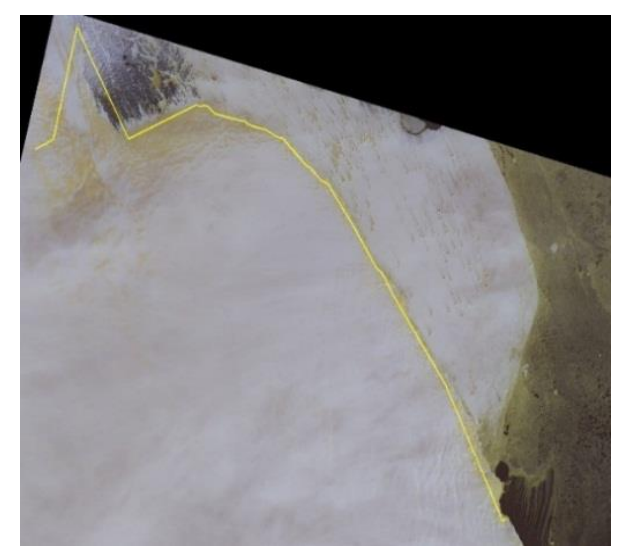

(b)

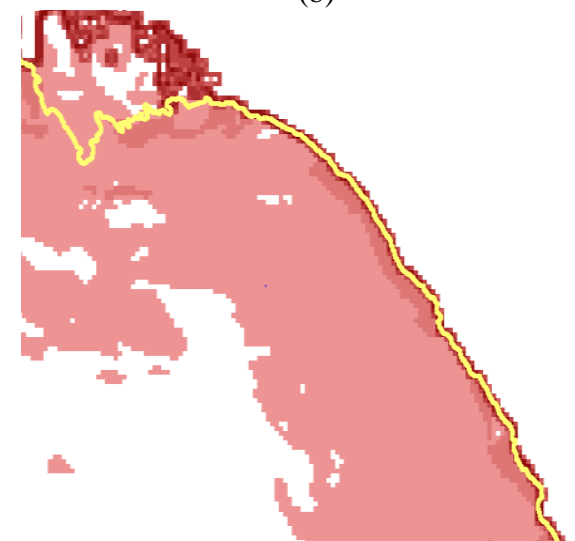

(d)

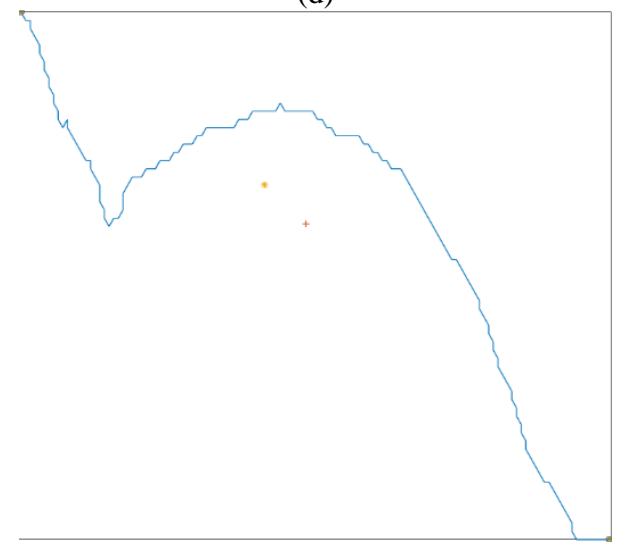

(f)

Fig.5. (a) Landsat8 standard deviation median filter of the initial grounding line area;(b) Regional linear fit results.(c) Croysat-2 elevation slope analysis, the red line is the location of the slope break;(d) The result of Croysat- 2 extraction(the red line) and the existing Moa product(the yellow line); (e) Comparison of the fusion result (red) with the MOA product (yellow) on the image; (f) The final extracted ground line

\section{EXPERIMENT AND ANALYSIS}

We chose a region near Zhongshan Station in Prydz Bay as the preliminary test data, ranging from $\left(66^{\circ} \mathrm{S}, 75^{\circ} \mathrm{E}\right)$ to $\left(70^{\circ} \mathrm{S}\right.$, $85^{\circ} \mathrm{E}$ ) shown in Figure 3, the area is also marked with a blue box in Figure 4 . We selected Landsat 8 OLI data from October 2015 and selected October 2015 Cryosat-2 elevation data. Using the elevation data to analyze the entire south pole gradient, the percentage and degree representation results are shown in the Figure 4, and the regions corresponding to the optical image are finally selected for fusion analysis.
Landsat8 optical data has rich texture features with spatial resolution of $30 \mathrm{~m}$, We can extract the grounding line with rich textures. Cryosat-2, as a newly launched satellite, has a high precision and long time sequence of elevation data, We first interpolate the elevation datas by interpolation algorithm and then do the plane fitting, we can get a more accurate slope analysis results. Fusion algorithm extraction of the groundling line with existing Moa products and MEaSUREs products in line with a high degree of integration accuracy, the accuracy of MOA products is not less than \pm 250 m, and the accuracy of MEaSUREs products is not less than $\pm 100 \mathrm{~m}$. There is no MEaSUREs product result in the selected study area, this article only compares the results with the MOA product. Landsat 8 
optical image extraction of the grounding results shown in Figure 5(a)(b). Grounding line results obtained by the slope analysis with cryosat-2 elevation datasets shown in Figure 5(c) and (d). The fusion of the optical image extraction area with the cryosat-2 elevation data analysis results in preliminary results shown in Figure 5(e) (red areas) (yellow line is MOA product ). The final extraction result is shown in Figure 5(f).

From Figure 5, it can be seen that the K-means algorithm extracts the ground line area based on the texture features of the optical image and most of the MOA product results are coincident. Only the upper left corner of the optical image texture features of complex region has certain deviation; through the Cryosat- 2 Elevation data is used for slope analysis. Figure 4 shows that the elevation data slope analysis results and the MOA products and MEaSUREs product results can be accurately matched on the large scale of the whole Antarctic Pole. By cropping, the slope analysis results of the corresponding study area in this paper are obtained and projected onto the same image, and most of the image area can be accurately overlapped. Only the slope analysis of the complex area in the upper left corner is biased, and the optical image and slope analysis results in this area has a certain degree of deviation, so by combining the two results, the fusion result is shown in Figure 5(e). The results of the MOA product are located in the fusion region, especially in complex area, the fusion result of the original two kinds of the extraction results have greater improvement, as a result of the merge is a regional. Since the fusion results in a region, we optimize the region by a certain improvement algorithm and finally obtain a linear result, as shown in Figure 5(f).

For large-scale space, the results of slope analysis are highly consistent with the results of MOA products. In this paper, for the two different data sources, the ground line of the South Pole can be obtained by using the two algorithms in the study area of this paper. We use the MOA product as verification data and calculates the geometrical distance between the fusion result and the corresponding point of the MOA product as a quantitative judgment basis for the accuracy of the fusion result. Eliminating extreme value in the calculation results of 1443.9 meters, the final calculation shows that the maximum distance between the fusion result and the corresponding point of the MOA product is 188.67 meters, we know that the accuracy of the MOA product is \pm 250 meters, and the grounding line area usually covers a range of several kilometers. Based on this, the fusion result has good reliability, it provides a reliable reference for us to use multiple data sources to extract a wide range of ground lines.

\section{CONCLUSION}

In this paper, according to the texture feature information of optical image, the image is firstly segmented by the K-means clustering algorithm, then the grounding line is extracted through the median filter; according to the gradient information of the Cryosat-2 elevation data, the gradient of the edge gradient is marked by the gradient analysis. The area serves as a grounding area. In addition to some of the smaller complex areas, the ground lines obtained by the two algorithms have a high coincidence with the MOA ground line products. Finally, the fusion algorithm can greatly improve the extraction results of complex areas. We compare the extraction results with MOA products, and we can also get the fusion results with better reliability. Therefore, the extraction algorithm and processing flow adopted in this paper are reliable, and the accuracy of the extraction results should be further improved. In the future work, more accurate data sources and processing methods will be combined, including the use of a wide range of SAR data and the InSAR technology with the highest accuracy of processing results.

\section{ACKONWLEDGEMENT}

This study is supported by the National Key R\&D Program of China, No. 2017YFA0603104, the State Key Program of National Natural Science of China, No. 41531069, the fundamental Research Funds for the Central University, No. 2042018kf0050, the China Postdoctoral Science Foundation, No. 2017M612512.

\section{REFERENCES}

Bamber J L, Gomezdans J L, Griggs J A, 2008. A new $1 \mathrm{~km}$ digital elevation model of the Antarctic derived from combined satellite radar and laser data - Part 1: Data and methods, 48(6):pp.372-375.

Christie, F. D. W., Bingham, R. G., Gourmelen, N., Tett, S. F. B., and Muto, A. 2016. Four-decade record of pervasive grounding line retreat along the Bellingshausen margin of west Antarctica. Geophysical Research Letters, 43(11), pp.57415749.

Depoorter, M. A., Bamber, J. L., Griggs, J. A., Lenaerts, J. T. M., Ligtenberg, S. R. M., and Broke, M. R. V. D., et al. (2013). Antarctic ice-shelf thickness, ice-shelf mask, and grounding line (datasets used in doi:10.1038/nature12567).

Dawson, G. J., and Bamber, J. L. 2017. Antarctic grounding line mapping from cryosat-2 radar altimetry. Geophysical Research Letters, 44(23).

Goldberg, D., Holland, D. M., and Schoof, C. 2009. Grounding line movement and ice shelf buttressing in marine ice sheets. Journal of Geophysical Research Earth Surface, 114(F4).

Gladstone, R. M., Lee, V., Vieli, A., and Payne, A. J. 2010. Grounding line migration in an adaptive mesh ice sheet model. Journal of Geophysical Research Earth Surface, 115(F4), - .

Hogg, A. E., Shepherd, A., Lin, G., Muir, A., and Drinkwater, M. R. 2017. Mapping ice sheet grounding lines with cryosat-2. Advances in Space Research.

Joughin, I., Shean, D. E., Smith, B. E., and Dutrieux, P. 2016. Grounding line variability and subglacial lake drainage on pine island glacier, antarctica. Geophysical Research Letters, 43(17), pp.9093-9102.

Kuijpers A, Nielsen T, 2014. Grounding Line. Springer Netherlands, 2014

Li, X., Rignot, E., Morlighem, M., Mouginot, J., and Scheuchl, B. 2015. Grounding line retreat of totten glacier, east antarctica, 1996 to 2013. Geophysical Research Letters, 42(19), pp.80498056 . 
Pattyn, F., Perichon, L., Durand, G., Favier, L., Gagliardini, O., and Hindmarsh, R., et al. 2013. Grounding-line migration in plan-view marine ice-sheet models: results of the ice2sea mismip3d intercomparison - escholarship. Journal of Glaciology, 59(215), 410.

Pattyn F, Docquier D, Durand G, et al, 2012. Effect of rapid grounding line migration investigated with $3 \mathrm{D}$ ice sheet-ice shelf models (MISMIP3d). EGU General Assembly Conference. EGU General Assembly Conference Abstracts, 2012.

Rignot, E., Mouginot, J., Morlighem, M., Seroussi, H., and Scheuchl, B. 2014. Widespread, rapid grounding line retreat of pine island, thwaites, smith, and kohler glaciers, west antarctica, from 1992 to 2011. Geophysical Research Letters, 41(10), pp.3502-3509.

Rignot, E., Mouginot, J., and Scheuchl, B. 2011. Antarctic grounding line mapping from differential satellite radar interferometry. Geophysical Research Letters, 38(10), pp.264265.

Rebesco, M., Domack, E., Zgur, F., Lavoie, C., Leventer, A., and Brachfeld, S., et al. 2014. Boundary condition of grounding lines prior to collapse, larsen-b ice shelf, antarctica. Science, 345(6202), 1354.

Rosenau, R., Schwalbe, E., Maas, H. -., Baessler, M., and Dietrich, R. 2013. Grounding line migration and high-resolution calving dynamics of Jakobshavn isbræ, west greenland. Journal of Geophysical Research Earth Surface, 118(2), pp.382-395.

Scheuchl B, Mouginot J, Rignot E, et al,2016. Grounding line retreat of Pope, Smith, and Kohler Glaciers, West Antarctica, measured with Sentinel - 1a radar interferometry data. Geophysical Research Letters, 43(16).

Schoof, C. 2007. Ice sheet grounding line dynamics: steady states, stability, and hysteresis. Journal of Geophysical Research Earth Surface, 112(F3).

Xie, H., Chen, L., Liu, S., Jin, Y., Liu, J., and Liu, S., et al. 2016. A least-squares adjusted grounding line for the Amery ice shelf using icesat and landsat 8 OLI data. IEEE Journal of Selected Topics in Applied Earth Observations \& Remote Sensing, 9(11), pp.5113-5122. 